\title{
IDENTIFICACIÓN DE RECURSOS TURÍSTICOS POTENCIALES IMPORTANTES POR CRITERIOS DE SINGULARIDAD IDENTITARIA Y UNIVERSAL. EL MUNICIPIO DE UGÍJAR EN LA COMARCA DE LAS ALPUJARRAS
}

\author{
Juan Luis Fernández-Quero* \\ Universidad de Granada \\ https://orcid. org/0000-0002-2987-4911 \\ Francisco Antonio Navarro Valverde* \\ Universidad de Granada \\ https://orcid. org/0000-0001-5033-7603
}

\section{RESUMEN}

La promoción de las áreas rurales es una cuestión primordial para luchar contra su despoblamiento. Actualmente existen deficiencias en la percepción del valor de los recursos propios existentes en muchos de estos territorios. Situación debida a factores como la falta de cultura territorial, profundización local y difusión investigadora de aquellos que pudieran poseer ciertas singularidades o aspectos de interés a diferentes escalas. La salvaguardia de la identidad territorial posibilita una evasión ante los procesos banalizadores conservando a su vez la riqueza patrimonial.

Palabras clave: Identificación, recursos endógenos; singularidad; autenticidad; identidad territorial; cultura territorial; rasgos internacionales; visitantes; desarrollo turístico.

Identification of important potential tourism resources by identity and universal singularity criteria. The municipality of Ugíjar in the Region of Las Alpujarras

\section{ABSTRACT}

The promotion of rural areas is a key issue to fight against their depopulation. Currently there are deficiencies in the perception of the value of own resources in many of these terri-

Fecha de recepción: 28 de noviembre de 2018

Fecha de aceptación: 22 de abril de 2019

* Departamento de Geografía Humana, Universidad de Granada. Campus de Cartuja, s/n. 18071 GRANADA (España).E-mail: juanluisfq@correo.ugr.es, favalver@ugr.es 
tories. Situation due to factors such as lack of territorial culture, local deepening and research dissemination of those which may have certain singularities or aspects of interest at different scales. The safeguarding of territorial identity makes possible an evasion before the banalizing processes while conserving the patrimonial wealth.

Keywords: Identification; local resources; singularity; authenticity; territorial identity; territorial culture; international features; visitors; tourism development.

\section{INTRODUCCIÓN}

Se entiende por recurso turístico todo elemento natural, toda actividad humana o todo resultado de esta actividad humana que puede (potencialidad) mover y generar un desplazamiento por motivos de ocio (Navarro Valverde, 2015). Siendo el producto turístico una interacción de prestaciones y elementos materiales e inmateriales que ofrecen unos aprovechamientos al cliente respondiendo a concretas expectativas e intereses. Comprende un conjunto de bienes o recursos, servicios y entornos, que distingue o emplea el visitante en los destinos a los que acude con la intención de complacer sus motivaciones de ocio (García Cuesta, 2003). Una vez atendidos estos conceptos básicos, es necesario hacer referencia al estado de la cuestión respecto a la utilización de la singularidad en estudios referentes a la valoración de recursos turísticos, existiendo una amplia variedad de trabajos que han logrado un uso de tal criterio.

En un primer momento, fue la Organización Mundial de Turismo (OMT) la que sienta las bases para realizar inventarios, cuantificar/cualificar los atractivos y estudiar los problemas propios de los recursos, proponiendo una jerarquización y su protección y ordenación (Navarro Jurado, 2016). Aquello que es excepcional y singular toma una gran relevancia en muchos de estos casos como se comprueba a continuación. La Unión Internacional de Organismos Oficiales de Turismo (UIOOT), en un trabajo de revisión a escala internacional, cita tres criterios de valoración básicos reincidentes en relación a la oferta potencial de una zona concreta: el grado de interés que posee sobre quién lo demanda, su rareza u originalidad, y su disponibilidad en el tiempo (renovables y no renovables) (UIOOT, 1970. En: Leno Cerro, 1993). El estudio de técnicas de evaluación turística de Leno (1993) amplía esta propuesta, hablando de técnicas analíticas, evaluación económica de los recursos y de preferencias de usuarios. Los métodos analíticos se basan en la rigurosidad y objetividad de los factores;y por otra parte, las técnicas basadas en las preferencias de los usuarios miden la importancia del recurso atendiendo a la opinión de turistas potenciales o reales. Cebrián Abellán y García González (2010) consideraron la relevancia de los pesos ponderados por medio de la singularidad o rareza, significación y su conservación. Aunque hay que tener presente que existe un importante grado de subjetividad cuando se valoran (Luque Gil y Navarro Jurado, 2011). Un ejemplo es el proyecto Sigturex en Extremadura. En los ámbitos rurales, se persigue, la posible recuperación de elementos identitarios, su puesta en valor, la aplicación de técnicas de interpretación, su integración en rutas y la mejora de su accesibilidad (Vera, López, Marchena y Antón, 2011). 
El presente trabajo discrimina la singularidad principalmente en dos vertientes; una por excepcionalidad distributiva de los caracteres del recurso y otra por importancia destacada a nivel supranacional de una o varias cualidades del bien. Tal visión tiene como finalidad crear un impacto en la población a partir de dichos aspectos potenciales con la intención de conseguir, en su caso, una revaloración de parte del patrimonio que poseen o al menos la suscitación de interés por conocerlo. Es momento de rescatar el concepto de Patrimonio Territorial entendiéndose como un conjunto de bienes naturales y culturales heredados en un espacio concreto, con un alto grado de aceptación y reconocimiento social (Ortega Valcárcel, 1999), por medio de un equilibrio en el medio ambiente que permite mantener los procesos ecológicos y naturales en demarcaciones con una presencia histórica antropizada (Feria Toribio, 2010). Añadiendo otras pormenorizaciones en las que en ocasiones se ven incluidos, como los premios internacionales, récord guiness, concursos gastronómicos y arquitectónicos, entre otros y reconocimientos de este tipo por distintas instituciones u organismos relevantes. Además estos podrían ser adheridos a una estrategia turística, si aún no lo están, adquiriendo a través de la ideología propuesta por la Estrategia Andaluza de Turismo Sostenible unas determinaciones en pro del desarrollo sostenible y por medio de la Agenda 21 Andalucía.

El turismo rural es una actividad en auge desde las décadas de los 80 y 90 del siglo XX (François, 2004; Sharpley, Sharpley, 1997), de manera que es apropiado nombrar por lo menos algunos factores que han permitido este crecimiento, como la búsqueda de la diferenciación y particularización en la oferta; el interés por valores relacionados con el "imaginario rural" (raíces, cultura ancestral, lo auténtico, calidad de vida, tranquilidad, paisajes, ...); el proceso de turistificación, extendiéndolo hacia los ámbitos rurales; la gran capacidad que tiene de generar efectos multiplicadores (Crosby, 1993); la potenciación por parte de las administraciones e instituciones públicas, como vía para favorecer el desarrollo y diversificación de los territorios rurales; y como medio para preservar el patrimonio natural y cultural. El trabajo realizado por la OMT (2004) en Europa ya muestra señales de las posibilidades del sector confirmando que su crecimiento anual viene siendo cada vez más relevante.

\section{METODOLOGÍA}

Partiendo de lo anterior, se busca detectar las principales singularidades de los recursos turísticos, a través de una metodología analítica, rigurosa y a partir de criterios geográficos; siendo aplicada en el contexto de una comarca rural, Las Alpujarras, y concretamente, en uno de sus municipios, Ugíjar, dentro de la provincia de Granada. En primer lugar, en el trabajo de gabinete se utiliza cualquier material que procede de una fuente fiable y que aporta información útil al respecto, desde artículos científicos, sistemas informativos, planes y trabajos sectoriales, medioambientales y territoriales. Además de páginas webs de instituciones y organismos especializados, por mencionar algunos como los que aparecen reflejados en los datos turísticos o la de los Grupos de Desarrollo Rural de La Alpujarra Granadina y Almeriense, proyectos locales y subregionales, revistas, manuales y distintos tipos de materiales (cartográficos, audiovisuales, ...). A destacar en el medio natural, el sistema Anthos, la Lista Mundial de Especies Amenazadas y el documento de 
bioclimatología perteneciente a la Junta de Andalucía. En lo sociocultural son representativas las guías en las que colabora el ADR, el Atlas de Patrimonio Inmaterial Andaluz o el documento de Patrimonio Mundial de La Alpujarra. El programa de ArcGis también ha sido necesario para desarrollar un mapa referente a la comarcalización.

En el trabajo de campo se ha obtenido información principalmente a través del Ayuntamiento de Ugíjar y la interacción con los diferentes actores y agentes territoriales, como pastores, cazadores, agricultores, sacerdotes, expertos locales, empresas y personas de distintas edades. Finalmente se recorren algunos territorios alpujarreños y se hace una gran inspección exhaustiva de recursos en el municipio de Ugíjar, obteniendo una gran galería fotográfica de tal circunscripción. Para discriminar los bienes se valoran sus caracteres investigando cualquier excepcionalidad reseñable que lo pueda extrapolar internacionalmente o que le presten un matiz diferencial propio que lo diferencia del resto identificándolo con un territorio específico. Tras las reflexiones llevadas a cabo, analizando los recursos por medio del criterio de singularidad identitaria y universal se justifican descartes que pueden parecer a priori significativos al respecto. Existe una gran dificultad y complejidad a la hora de discernir cuando la cualidad de un recurso es verdaderamente excepcional dentro de aquellas que pueden ser consideradas como propias, algo que se extrapola por ejemplo a las variedades de cultivo tradicionales o a los juegos populares, entre otras muchas situaciones, donde generalmente faltan estudios específicos. Por lo tanto se buscan manifestaciones muy originales o con un reconocimiento internacional. En las descripciones normalmente sólo se manifiesta la cualidad que en cada caso ha sido definitoria para superar el proceso de criba del criterio propuesto.

\section{LOS HABITOS MOTIVACIONALES DE LOS VIAJEROS COMO FACTOR DE OPORTUNIDAD PERCEPTIVA SOBRE LOS RECURSOS EN LA ALPU- JARRA}

Antes de empezar a detallar los datos es necesario argumentar que la mayoría de estos se han comparado a nivel provincial, por ámbitos subregionales, ya que entendemos que es lo más apropiado para obtener una prospección más acertada al respecto. Además se centran en la zona granadina, con la intención de ofrecer una mayor aproximación de la situación que sufre esta parte de La Alpujarra donde se encuentra el municipio de Ugíjar. La división transciende a la zona Norte de la provincia (Altiplano, Guadix-Marquesado y Montes Orientales), la Costa Tropical, La Alpujarra, el Poniente (Alhama, Loja) y Sierra Nevada, la misma que muestran las respectivas fuentes, quedando Granada Capital y su entorno en otro bloque que se puede tener en cuenta en las comparaciones pero que es ya distinto al de la ruralidad. Se han anotado en las tablas (1 y 2) los resultados cuantitativos que han destacado en cada caso, indicando sobre todo cuando se muestran cifras por debajo o por encima del promedio. Añadir que cuando no se específica en tales tablas, el dato que aparece corresponde a la media de turistas y excursionistas. Una vez realizadas las aclaraciones se puede proceder a la descripción de los porcentajes más relevantes.

El Patronato Provincial de Turismo de la Provincia de Granada (2016) en su memoria anual de actividades hace mención al turismo rural como una de las tipologías que más ha crecido en los últimos años. La demanda rural en la provincia de Granada varía de la 
ofrecida en otras por tener un mayor porcentaje de aquellos que hacen senderismo $(30,0 \%)$ y la visita a parques naturales $(27 \%)$ (Tabla 1). En tercer lugar aparece la observación de la naturaleza $(19,6 \%)$ que mantiene una gran distancia con las dos primeras actividades y las restantes (Tabla 1). El conocimiento del destino se produce principalmente por tres medios, la recomendación de amigos y familiares $(33,5 \%)$, la experiencia propia $(30,4 \%)$ y es de recalcar las guías especializadas $(18,4 \%)$ con el mayor porcentaje comparativo entre provincias alcanzando la tercera posición (Tabla 1) (Junta de Andalucía, 2003b). Estas anotaciones se asientan sobre uno de los estudios más completos por provincias que la Consejería de Turismo, Comercio y Deporte ha realizado en la temática. Las principales motivaciones o segmentos turísticos del viajero en La Alpujarra son el turismo rural $(81,2 \%)$, el ecoturismo integrado en el de naturaleza $(27,15 \%)$ y el de ocio $(25,4 \%)$ (Tabla 1). La tendencia ascendente más llamativa es la promovida por el gastronómico y/o enoturismo $(23,4 \%)$, siendo estas tres proporciones (Turismo rural, ecoturismo y turismo gastronómico y/o enoturismo) mucho más significativas que la media provincial y superando claramente de manera individual a otros ámbitos subregionales de la provincia (Tabla 1). A lo que hay que añadir el despunte que ofrece junto con Sierra Nevada en la procedencia nacional de los visitantes $(96,1 \%)$, estando por debajo de la media en lo que ha extranjeros se refiere, resto de la UE-28 $(2,8 \%)$ y el resto del mundo $(1,2 \%)$ (Tabla 1). Hay que resaltar que son principalmente los turistas nacionales y no los excursionistas de origen español los que declinan la balanza en este aspecto, indicando una predominancia enérgica principalmente del turista nacional frente a unos mejorables resultados del extranjero. Datos que acaban influyendo en las pernoctaciones (Tabla 2). Todo esto viene a confirmar ciertas tendencias de años anteriores (Observatorio Turístico de Granada, 2016).

\section{Tabla 1}

\section{CARACTERES DE LAS VISITAS EN DIFERENTES ESCALAS ESPACIALES. COMPARATIVA PROVINCIAL Y POR ÁMBITOS SUBREGIONALES 2016}

\begin{tabular}{|l|l|c|l|l|c|}
\hline \multicolumn{7}{|c|}{ RECURSOS, COSTUMBRES Y PROCEDENCIA DEL VIAJERO } \\
\hline \multicolumn{7}{|c|}{ Por secuencia de prevalencia } & $\%$ \\
\hline \multicolumn{1}{|c|}{ Provincia de Granada } & $\%$ & \multicolumn{1}{c|}{ La Alpujarra } & $\begin{array}{l}\text { Mejora los } \\
\text { datos de } \\
\text { la media } \\
\text { subregional } \\
\text { incluida la } \\
\text { capital }\end{array}$ & 81,2 \\
\hline Senderismo & $\begin{array}{l}\text { Mejora el } \\
\text { dato a la } \\
\text { media de } \\
\text { provincias }\end{array}$ & 30,0 & Turismo rural & 27,2 \\
\hline $\begin{array}{l}\text { Visita a } \\
\text { parques } \\
\text { naturales }\end{array}$ & 27,0 & $\begin{array}{l}\text { Ecoturismo integrado en la } \\
\text { naturaleza }\end{array}$ & & \\
\hline $\begin{array}{l}\text { Observación } \\
\text { de la } \\
\text { naturaleza }\end{array}$ & 19,6 & Ocio & & 25,4 \\
\hline
\end{tabular}




\begin{tabular}{|c|c|c|c|c|c|}
\hline \multicolumn{6}{|c|}{ Difusión, expansión exponencial de sectores y procedencia de las visitas } \\
\hline Medios de difusión & $\%$ & $\begin{array}{l}\text { Principales } \\
\text { crecimientos }\end{array}$ & $\%$ & $\begin{array}{l}\text { Origen de } \\
\text { la demanda } \\
\text { Alpujarra- } \\
\text { Sierra Nevada }\end{array}$ & $\%$ \\
\hline $\begin{array}{l}\text { Recomendación de } \\
\text { amigos } \\
\text { y familiares }\end{array}$ & 33,5 & $\begin{array}{l}\text { Gastronomía } \\
\text { y/o enoturismo }\end{array}$ & $\begin{array}{l}23,4> \\
\text { media } \\
\text { ámbitos } \\
\text { subre- } \\
\text { gionales }\end{array}$ & $\begin{array}{l}\text { Nacional> } \\
\text { media ámbitos } \\
\text { subregionales } \\
\text { incluida la } \\
\text { capital }\end{array}$ & 96,1 \\
\hline Experiencia propia & 30,4 & & $\begin{array}{l}\text { incluida la } \\
\text { capital }\end{array}$ & $\begin{array}{l}\text { Resto de } \\
\text { Europa < } \\
\text { "media..." }\end{array}$ & 2,8 \\
\hline Guías especializadas & $\begin{array}{l}18,4>\text { media } \\
\text { de provincias }\end{array}$ & & & $\begin{array}{l}\text { Resto del } \\
\text { mundo< } \\
\text { "media..." }\end{array}$ & 1,2 \\
\hline
\end{tabular}

Elaboración propia a partir de los datos de la Junta de Andalucía y el Observatorio Turístico de Granada.

Tal memoria anual refleja más datos que son de interés para el presente trabajo ya que ofrecen detalles de la conducta del visitante y de sus preferencias, aspectos que también influyen a la hora de apostar por una estrategia turística de revalorización de los recursos potenciales. Por esta razón, se verifica la presencia del siguiente cuadro (Tabla 2). Llama la atención la particularidad presentada entre ambos tipos de viajeros, cuando los excursionistas superan a los turistas en visitas. No obstante, hay que argumentar que los otros porcentajes de las demás delimitaciones subregionales no se disponen tan distantes de esta realidad, exceptuando la Costa y Granada capital junto a sus alrededores (Observatorio Turístico de Granada, 2016). Descripción habitual en la primera por el fomento de la segunda residencia vacacional veraniega. En Granada, en cambio, existe un progresivo aumento de pernoctaciones que coinciden con un incremento paralelo en los últimos años del turista extranjero, llegando a superar al nacional cuestión inusual antes de 2014 para la capital (Ayuntamiento de Granada, 2018). El turista alpujarreño pernocta menos que la media subregional provincial, razón que se aprecia influenciada por la idea errónea que se ha implantado por los turoperadores de que La Alpujarra y concretamente en este caso la Granadina se puede conocer en un día (Rodríguez, 2008). Organizando viajes de una jornada a zonas alpujarreñas más próximas con el municipio de Granada, como Lanjarón y el Barranco del Poqueira y dando a entender frecuentemente en su publicidad y anuncios que La Alpujarra es solo estos enclaves. Además hasta las señalizaciones por carretera y los folletos de las administraciones públicas parecen seguir esta inercia, atesorando entonces culpabilidad en la consecución de esta circunstancia impulsando también ese pensamiento y apostando ya desde hace décadas por tal planificación, aspecto que conocen bien los ayuntamientos del resto de la comarca. Ello ha incentivado a otras circunscripciones, como las de La Alpujarra granadina oriental, que quieren crecer en tal modalidad, a centrarse en la captación de visitantes de la provincia de Almería. Para ello aprovechan su 
situación estratégica que sirve de enlace entre ambas manteniendo numerosas conexiones funcionales debido a su proximidad al poniente almeriense (Fernández de Córdoba, Clusa y Oriach, Feria Toribio y Vega González, 1986).

Tabla 2

OTROS HÁBITOS A TENER EN CUENTA EN LOS VIAJEROS CON DESTINO A LA ALPUJARRA MEDIANTE CONSTRASTES POR ÁMBITOS SUBREGIONALES 2016

\begin{tabular}{|c|c|c|c|}
\hline \multicolumn{4}{|c|}{ TIPOLOGÍA DE VISITANTES Y TENDENCIAS EN ALGUNAS PRÁCTICAS } \\
\hline \multicolumn{4}{|l|}{ AÑO: 2016} \\
\hline Turista $(\%)$ & $\begin{array}{l}\text { Excursionista } \\
(\%)\end{array}$ & $\begin{array}{l}\text { Asistencia a eventos y } \\
\text { espectáculos }(\%)\end{array}$ & $\begin{array}{l}\text { Intención o compra de productos de } \\
\text { artesanía (\%) }\end{array}$ \\
\hline 49,4 & 50,6 & 29,3 & 76 \\
\hline \multicolumn{2}{|l|}{ Descripción } & Tipología (\%) & Tipología (\%) \\
\hline \multirow{3}{*}{\multicolumn{2}{|c|}{$\begin{array}{l}\text { Único ámbito subregional } \\
\text { de la provincia junto a } \\
\text { Sierra Nevada que en la } \\
\text { comparativa con Granada } \\
\text { y sus alrededores, el Norte } \\
\text { de la provincia, la Costa y } \\
\text { el Poniente los turistas no } \\
\text { superan a los excursionistas }\end{array}$}} & $\begin{array}{l}1^{\circ} \text { Feria de Muestras } \\
53,7 \text { (Muy por encima } \\
\text { de los demás ámbitos } \\
\text { subregionales incluida la } \\
\text { capital) }\end{array}$ & $\begin{array}{l}1^{\circ} \text { Comestibles artesanales } \\
89,55 \text { (Muy por encima de la media } \\
\text { subregional incluida capital) }\end{array}$ \\
\hline & & $\begin{array}{c}2^{\circ} \text { Eventos religiosos } \\
20,35\end{array}$ & $\begin{array}{l}2^{\circ} \text { Alfombras y jarapas } \\
28,8 \text { (Muy por encima de la media } \\
\text { subregional incluida capital) }\end{array}$ \\
\hline & & \begin{tabular}{|c}
$3^{\circ}$ Fiestas populares \\
12 (siendo solo un \\
1,9 el porcentaje de \\
excursionistas, muy por \\
debajo de las de más \\
subregiones rurales)
\end{tabular} & $3^{\circ}$ Cerámica \\
\hline
\end{tabular}

Elaboración propia a partir de la encuesta de demanda del Observatorio Turístico de Granada.

En cuanto a la presencia de visitantes en acontecimientos prácticamente 3 de cada 10 personas participan, siendo en la feria de muestras este valor casi 4 veces mayor en los excursionistas que en los turistas alcanzando en la media lo adscrito en la Tabla 2. Se puede observar que algo más de la mitad de los visitantes que asisten a eventos se incorporan a tal propuesta de muestras (Tabla 2). Los religiosos atraen a ambos en proporciones parecidas alcanzando un segundo lugar en este empaque (Tabla 2). Viéndose otra irregularidad en la capacidad de atracción de los viajeros por parte de las fiestas populares, siendo hasta 10 veces mayor en el caso de los turistas logrando una media del 12\%, estando muy por debajo de las subregiones rurales analizadas en los excursionistas que asisten a estas (Tabla 2). La mayoría tiene la intención o compra productos de artesanía enfatizando en aquellos que se prestan a la gastronomía, prácticamente 9 de cada 10, consecutivamente de 
ciertos textiles con el 28, $8 \%$ y un $18,9 \%$ que obtienen los de cerámica (Tabla 2). Argumentar también que se duplica la proporción de turistas que se hace con enseres artesanos a la de excursionistas. Destaca teniendo mayor éxito respecto al resto de subregiones en la atracción a ferias de muestras, comestibles artesanales, alfombras y jarapas (Tabla 2). En definitiva (Tablas 1 y 2), se pueden dirimir ciertos comportamientos reveladores que permiten la alineación de un perfil general de las personas que vienen a tal enclave.

\section{PRINCIPALES RECURSOS TURÍSTICOS PRESENTES EN EL CONTEXTO TERRITORIAL ALPUJARREÑO}

La Alpujarra es un territorio montañoso situado en la vertiente sureña de Sierra Nevada, conformada por valles profundos, posee según Castillo Martín (2004) la carretera más alta de Europa (Collado de La Carihuela, GR-420; junto al pico del Veleta) y se encuentra compartida entre dos provincias, Granada y Almería (Mapa 1). Se recuerda que se ha plasmado la necesidad de que el recurso sobresalga al menos en uno o varios caracteres con determinaciones llamativas a una escala supranacional o una cualidad identitaria considerada como propia y que no se repite de esta forma en otros territorios dentro de su agrupación (tipología de recurso), incorporando reconocimientos internacionales de distinto tipo. Para ello se elabora una investigación a través de los principales componentes territoriales, como el medio biofísico, el medio socioeconómico y sociocultural. La Alpujarra adquiere algo que no se localiza en todas las regiones quedando especialmente representada por su patrimonio histórico-cultural, aunque posee también un gran valor ecológico-ambiental.

\section{Mapa 1 \\ DELIMITACIÓN COMARCA ALPUJARRA}

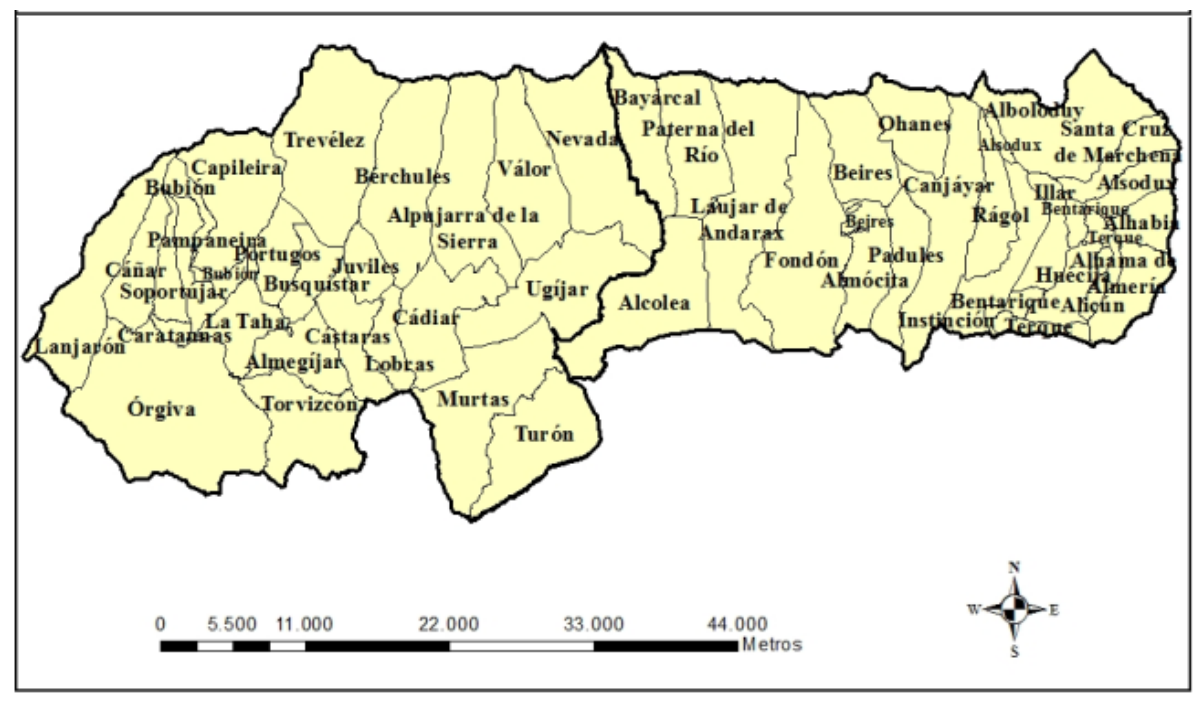

Elaboración propia a partir de los datos del DERA y MDA 100. 


\subsection{La esencia resultante de una forma de vida vernácula y su representación en un paisaje cultural excepcional}

El primer elemento clave es el fuerte sentimiento que emana del "espacio-vivido" que fue percibido por los viajeros románticos a través del aislamiento que sufría la zona, justificado por su situación entre cuatro montañas, postergando su desarrollo industrial hasta pasada la mitad del siglo XX. Historiadores como Titos Martínez y Martín Vida (2007) dan fe del extraordinario fenómeno a través del aumento exponencial de obras escritas sobre el enclave en este periodo. El éxodo rural de 1950 y la incorporación de nuevos pobladores movidos por el turismo progresivamente desde 1960 no favoreció una mayor conservación del entorno patrimonial. El proteccionismo del régimen unido a las cuestiones anteriores propició que sus gentes vivieran prácticamente como lo habían hecho antes de la revolución industrial, cuestión muy inusual que impresionó en sobremanera a estos extranjeros. Fue tal la fascinación, que realizaron con verdadero detalle biografías de la forma de vida y del carácter de los alpujarreños. Estos documentos adquirieron un gran valor y pronto se empezó a visualizar a La Alpujarra desde el extranjero como algo extraordinario. El etnólogo y antropólogo suizo Christian Spanhi en su obra L'Alpujarra: Secréte Andalousie (1959) expresa una frase que representa dicha situación: "La Alpujarra es el rincón del planeta donde la vida tiene todavía una explicación”.

Esa asimilación del vivir se ha ido perdiendo, aunque aún quedan algunos pueblos donde ciertas personas, la mayoría jubilados, siguen ejecutando acciones tradicionales, cultivando con variedades autóctonas, utilizando la fuerza animal como transporte y labrando la tierra con las mismas técnicas. La falta de población joven cada año se acentúa más. Así nos adentramos en los verdaderos paisajes vivientes con forma de humano en la comarca: Las personas; que contienen la sabiduría, el arte y la historia de un mundo legendario. Gente como los confiteros, los campesinos que conocen el campo como la palma de su mano, los pastores que transitan las cañadas reales, ...que continúan con las mismas tradiciones y con los mismos hábitos antiguos en muchos casos como hace 500 años. Aquellos que preservan lo autóctono, la identidad, las antiguas disposiciones del regadío, las formas de distribución de los cultivos y su trato, los burros, los corrales de antaño, ...que sepan que son verdaderas reliquias que cuando desaparezcan se llevaran consigo los paisajes y el patrimonio de una región singular y cargada de historia.

Es momento pues de desvelar el otro gran factor diferenciador que procede precisamente de esa capacidad desde hace siglos de aprovechar los recursos endógenos como único medio de supervivencia. Este se puede definir de forma generalista como paisaje cultural (Tabla 3). Termino que promulga la evolución de la concepción del patrimonio hasta incluir bienes contemporáneos, procedentes del trabajo y a través de una configuración espacial de los recursos así como la consideración del propio territorio en su dimensión cultural por medio de figuras específicas. A lo que se añade la fusión entre patrimonio natural y cultural (Silva, Fernández y Mata, 2018). Existen ciertos componentes que los expertos a través del proyecto culturmed en su anexo $1^{\circ}$ y anexo $2^{\circ}$ (Heritage, 2014) justifican como prioridad a preservar dignos de ser adscritos como Patrimonio Mundial de la Humanidad por la UNESCO. Las características paisajísticas para la Declaración de la UNESCO según Martínez Arnáiz, Baraja Rodríguez y Molinero Hernando (2019) 
deben de ir acompañadas de una potencialidad económica y requiere de una entretenida burocracia. Algo que podría crear cierta desigualdad a la hora de llevarla a cabo, independientemente del valor cultural que posea este, teniendo en cuenta los estados y las regiones a las que pertenecen.

Los sistemas de policultivos con muros de piedra seca donde abundan los linderos con árboles como los almecinos de gran sujeción, han sido tradicionalmente parte irrefutable del paisaje alpujarreño. Esta alternativa de bancales, acequias para riego y cultivos herbáceos adaptados al terreno forman uno de los caracteres arraigados del ámbito siendo la cultura de regadío islámica fundamental en su configuración y aprovechamientos (Trillo San José, 1999). Pero existe un principio clave en este agrosistema que no tiene parangón en ningún otro lugar con este nivel de eficiencia y desarrollo (sólo se le asemeja Urcuquí en los Andes ecuatorianos) que no sea Sierra Nevada con su principal ejemplo en La Alpujarra siendo la base de este medio. Se trata de las denominadas acequias de careo, una manera sofisticada de trasladar el agua de las cumbres al piedemonte a través de infraestructuras hidráulicas de tierra y piedras. La infiltración en el recorrido y por los propios caladeros es lo que posibilita que el agua paulatinamente descienda hacia distintas cotas llegando a las terminaciones de menor altitud cuando más se necesita. Tales surgencias aparecen en muchas ocasiones en verano posibilitando una agricultura próspera.

Por otro lado, surge como medio persuasivo la arquitectura vernácula, alcanzando la excepcionalidad universal cuando cumple una serie de consideraciones. Estas se recogen en un documento posterior que recrea la consultora Heritage (2015) para el proyecto Poctefex. Es fundamental que los "terraos" sean planos y estén compuestos en su superficie de launas con composición autóctona de forjados, a la vez que las paredes sean blancas estando orientadas las viviendas al sur. Los muros deben ser de piedra, barro, argamasa y yeso, pudiendo faltar en ocasiones alguno de los dos últimos. El techo ha de tener vigas de madera con alfarjías de este componente en la parte septentrional y de cañizo en el sur, sobre las que descansan lajas de piedra y los materiales de compactación anteriormente mencionados. En atención a los veriles, nombrar que normalmente son lajas de pizarra equilibrando su peso gracias a un contrapié de fuertes piedras en donde se añaden los cuerpos con capacidad de untamiento antes nombrados. Los huecos que aparecen en la pared poseen pequeñas dimensiones y una forma cuadrangular con la misión de introducir algo de luz a ciertas zonas de la casa, posteriormente se desarrollan en las viviendas ventanas que normalmente se hacían con madera y siempre eran algo más altas que anchas. Las puertas son de madera y en su proceso de montaje se usan principalmente distintas proporciones de clavería, aquellas que tenían subdivisiones en la trama alta se circunscriben normalmente a las tradicionales puertas de corral y principalmente de cuadra. En las chimeneas se pueden encontrar diferencias entre el norte, cónicas con "castigadera" de laja de piedra y sur, cuadrangulares con cubierta pedregosa, ambas son planas.

En muchas ocasiones se cometen fallos a la hora de rehabilitar o imitar las construcciones alpujarreñas, integrados ya en numerosos pueblos, produciendo una banalización de la arquitectura tradicional. Parte de La Alpujarra está protegida gracias a la declaración en 1982 del Conjunto Histórico del Barranco del Poqueira formado por Capileira, Bubión (reconocimiento internacional de la red "Cittaslow") y Pampaneira junto al Sitio Histórico de la Alpujarra Media Granadina y La Tahá en 2007. Tratándose del ámbito histórico- 
patrimonial protegido más grande de Europa, lo que da significación de su importancia (SGOTU et CEPT, 2014). Aunque esto no ha reflejado un respeto absoluto por la mayor originalidad de las infraestructuras. Es lícito además argumentar que existen bienes que alcanzan otros caracteres realmente llamativos por medio de los criterios en los que se basa tal documento. Como ejemplo las aguas mineromedicinales de Lanjarón (por variedad de aguas mineromedicinales en manantiales en un solo balneario, siendo referencia a nivel supranacional en este aspecto), incorporando tal municipio en el museo la representación de la arquitectura del agua (reconocimiento internacional). Agregar una situación verdaderamente excepcional en la tradición de la cultura budista de occidente (reencarnación de lamas y paso de peregrinación atractivo a nivel europeo), se trata del caso de Osel que da lugar al centro Osel Ling.

\subsection{El patrimonio inmaterial}

Una vez expuestas las cuestiones referentes al altísimo valor del patrimonio cultural tangible inmueble y a esa forma de vida adaptativa tan auténtica que desencadena todos los demás procesos, es preciso volver a redundar en cuestiones como el patrimonio inmaterial y la gastronomía. La UNESCO define el patrimonio inmaterial como representaciones, expresiones, usos, conocimientos y técnicas junto a objetos, artefactos, instrumentos y espacios culturales de los que forman parte que las comunidades, los grupos y a veces los individuos reconocen como su patrimonio cultural. Se trasmite por generaciones y se recrea ininterrumpidamente por las comunidades y grupos según su entorno, entrando en contacto con su naturaleza e historia, otorgándole un sentimiento de comunidad e identidad que contribuye a promulgar el respeto por la creatividad humana y la diversidad cultural (UNESCO, 2003a; Citado por: Carrera, 2009b). Tras la consulta de una gran variedad de fuentes, a destacar Carrera, 2009a; Instituto Andaluz de Patrimonio Histórico, 2012; Espinosa Carmona, 2012 y la web generada a partir de la información recogida por el ADR de La Alpujarra Almeriense (Disponible en: http://www.alpuguia.com/); así como otras requeridas por los bienes específicos, es posible reflexionar sobre la gran cantidad de manifestaciones presentes en este territorio. No obstante, el Instituto Andaluz de Patrimonio Histórico por medio de Carrera (2009a) hace una discriminación por importancia ante tanta diversidad, al menos por el momento. Argumentando que no se registra todo lo que existe sino algunas representaciones de las tipologías dominantes de elementos y las expresiones más significativas, atendiendo a su valor identitario y a que constituyan un hecho social total, teniendo siempre en cuenta la valoración que se les otorga por la población.

Sin embargo, tal atlas expone algunas diferencias con la selección realizada por los autores de este trabajo que se han visto relegados a elegir por los criterios de singularidad y reconocimiento del elemento. Optando por aquellos que creemos son más relevantes, justificando cada decisión propuesta. En primer lugar, dentro de los rituales festivos se han considerado tres manifestaciones sobresalientes; la romería de la Virgen de la Nieves en su recorrido Trevélez-Mulhacén (una de las romerías más altas de Europa e incluso del mundo con una gran tradición y una relación muy específica con el espacio geográfico, fusiona los elementos naturales con lo divino). La advocación de la Virgen del Martirio 
(Tabla 5) (véase apartado 5. La importancia de la identidad territorial. La excepcionalidad potencial del municipio de Ugíjar) y por último la Santa Cruz de Canjáyar (la tradición plasma la presencia de una reliquia con trocitos de madera de la verdadera Cruz de Cristo, el papa reconoció un año jubilar con indulgencia plenaria a los fieles que la visitaran). En lo concerniente a los modos de expresión se han registrado 3 con referencias internacionales importantes que no se supeditan sólo a este espacio geográfico. Todos bajo el reconocimiento de la UNESCO como Patrimonio Mundial Inmaterial de la Humanidad (UNESCO, 2018b), son el flamenco (2010) (Tabla 4), la dieta mediterránea (2013) (Tabla 4) y conocimientos y técnicas del arte de construir muros en piedra seca (2018) (Tabla 4).

Único de esta región sí es el léxico alpujarreño (Tabla 3), es de interés mencionar que en la actualidad investigadores como Juan Carlos Maroto de la Universidad de Granada siguen recopilando formas de manifestaciones coloquiales y palabras para ampliar e impedir la pérdida de estos vocablos. El último eslabón es el que se refiere a la alimentación y cocinas. Debido a la gran variedad de productos tradicionales y platos gastronómicos que es posible especificar incluso a cada pueblo, se optará por adscribir aquellos que posean un reconocimiento o alguna diferenciación internacional, a lo que se complementa la situación de que muestren una estrecha relación con su entorno tanto en la materia prima como en la elaboración del producto otorgándole una calidad concreta por su unión, el saber y el oficio que se manifiesta junto con la identidad exclusiva en ese territorio. Una máxima distinción es la Denominación de Origen Protegida y dentro de esta se han seleccionado los que se adscriben por una gran excepcionalidad. Mostrar en esta perspectiva la Miel de Granada (Tabla 3) reconocida bajo esas siglas a nivel andaluz y europeo. La singularidad de este producto reside en su distribución geográfica, que es factiblemente la única en el mundo que en un espacio tan reducido de unos $40 \mathrm{~km}$ alcanza una variabilidad de al menos 4 pisos bioclimáticos. Desde la costa a las cumbres de Sierra Nevada a través de una trashumancia vertical (Ministerio de Agricultura, Pesca y Alimentación, 2016) las abejas tienen la posibilidad de interaccionar con numerosísimos vegetales específicos de cada bioclima y con endemismos propios.

Los vinos son el otro miembro inherente fundamental de la enmarcación, quizás los premios internacionales no sean la manera más adecuada para revelar el nivel de un vino, pero es la más habitual para dar reconocimiento y fama internacional a la bodega. Ya que a veces las más prestigiosas son las que tienen un mayor respaldo económico que les permite presentarse a más concursos y pagar más títulos. Estos últimos relativamente abundantes para ciertos detractores de esta tipología de evaluación, aunque de cara al público afirman parezca lo contrario, lo mismo suele ocurrir con otros concursos gastronómicos. Pero también es cierto que sea más complejo o no ser galardonado, de los presentes los mejores se llevan los más distinguidos reconocimientos. Dentro de la Denominación de Origen Protegida de Vinos de Calidad de Granada existe una bodega alpujarreña sobresaliente en lo que se refiere a reconocimientos internacionales. Se trata de los vinos de la denominada Dominio Buenavista ubicada en la zona granadina, que además posee la producción y la bodega dentro del municipio de Ugíjar (Tabla 4). Existen otras, en la parte almeriense, que también poseen algún reconocimiento de este tipo como ocurre dentro de la Incidencia Geográfica Protegida de Laujar-Alpujarra con las Bodegas y Viñedos Laujar (intención ecológicos), la de Selección de Vinos de Fon- 
dón (Tetas de La Sacristana) y la del Cortijo De La Vieja. En la Incidencia Geográfica Protegida Ribera del Andarax se reconoce a la Bodega de Alboloduy. Con ventas de ecológicos la de Tetas de La Sacristana, Bodegas Cortijo Fuentezuelas, el Cortijo de La Vieja y la de Alboloduy. En cuanto a otros alimentos con premios internacionales en La Alpujarra destacar los quesos, concretamente el de la entidad Venta del Chaleco-Lácteos Lanjarón S. L en la Alpujarra Granadina con dos premios. Por último, argumentar la importancia del plato alpujarreño (Tabla 3) creado en La Alpujarra en el siglo XX, se ha convertido en el emblema de su gastronomía, conocido en otras provincias y por turistas de diferentes lugares del mundo.

\subsection{La biodiversidad}

Es conveniente señalar que aparecen municipios alpujarreños, concretamente los más serranos adheridos a Sierra Nevada, que se sitúan dentro de la Reserva de la Biosfera de la UNESCO, teniendo por tanto un reconocimiento internacional como enmarcaciones donde se combina la diversidad biológica junto con la riqueza cultural. Posee también la delimitación a nivel europeo, con las figuras Zona de Especial Protección para las Aves (ZEPA) y Lugar de Importancia Comunitaria (LIC). Un paraje excepcional en la comarcalización que los autores realizan, que en este caso afecta al territorio de Torvizcón, es el de la Haza del Lino, también limítrofe a Órgiva. Se trata del bosque de alcornocales más alto y muy posiblemente consigue ser el que más al sureste se sitúa de Europa, siendo uno de los principales reductos de esta especie en el sureste ibérico (Valle, Madrona, Salazar, 1993; Fernández Ondoño et al., 2015).

Un aspecto clave que se señala en el momento de analizar la biodiversidad de un territorio son los endemismos, gracias a ellos se pueden conocer las particularidades del área analizada. Se utilizan las unidades corológicas existentes principalmente mediantes los sectores presentes para plasmar la realidad dada en cada caso. En este concreto se dan influencias del sector nevadense, el alpujarreño-gadorense y en el extremo este el sector almeriense, concretamente el subsector almeriense occidental, manteniendo cada zona una serie de fauna aparejada. Existen variaciones entre diversos expertos en la cuantificación de tales miembros, en el caso de la flora y la fauna, se conocen estudios que concretan unas cifras al respecto que pueden servir de orientación. En referencia a lo vegetal, según lo extraído del documento de Mota, Cabello, Dyonantey Cueto (1999) se alcanzan los 265 endemismos, de los cuales 48 serían exclusivos de los distritos nombrados. En Junta de Andalucía (2003a) se pueden apreciar los endemismos también por subsectores, dando como resultado 98 especies, con 4 propios alpujarreños. Aunque se ha comprobado a través del Sistema Informativo Anthos de Plantas de España (www.anthos.es) la presencia distintiva aparejada al área de una de las cuatro.

La información disponible para la circunscripción en cuanto a fauna si se analiza de forma conjunta y relacional por subsectores a través de los trabajos Junta de Andalucía, 2010, Durán, 2010 y Mota et al., 1999 expone unas variaciones que se especifican entre unos 194 y 217 endemismos. De tal forma que se puede afirmar que la Alpujarra es una de las comarcas que alberga mayor número de endemismos de Europa (Instituto Geográfico Nacional y Asociación de Geógrafos Españoles, 1990), al menos un total de 292 ende- 
mismos propios de los distritos biogeográficos de los que forma parte, no así específicos de la propia delimitación. Por su parte, el portal del Ministerio de Agricultura, Pesca, Alimentación y Medio Ambiente concreta para Sierra Nevada aproximadamente unos 66 taxones vegetales (160 endémicos no exclusivos) y 80 individuos de fauna propios que sólo se encuentran en este macizo. La gran mayoría de ellos adheridos también en la comarca, además esta incorpora transmisiones de fuera de la sierra que la hace incluso más variable pero menos singular, ya que posee un mayor aporte de diferentes unidades estructurales y biogeográficas.

Una vez descritas las potencialidades de la comarca ha llegado el momento de acotar tal investigación a nivel municipal, concretamente en Ugíjar, que como se ha comprobado comparte similitudes con la comarca, centrándose en los que aparecen en tal circunscripción. Cuestión que se relaciona con la lucha contra la banalización de los territorios.

\section{LA IMPORTANCIA DE LA IDENTIDAD TERRITORIAL. LA EXCEPCIONA- LIDAD POTENCIAL DEL MUNICIPIO DE UGÍJAR}

La pérdida progresiva de la originalidad de las circunscripciones se ha visto favorecida por el proceso globalizador (Alburqueque, 1999) generando una pasividad en el aprovechamiento de los recursos propios. Este hecho llega a su máxima criminalización cuando se trata de bienes únicos y que por tanto no se pueden encontrar en otras zonas con tal expresión o apego. Gracias a la facilidad de uso, velocidad y el poco coste que han alcanzado los sistemas de transporte es viable la exportación de mercancías. El sistema capitalista en su concepción general contrarresta el vínculo de la calidad frente al de la producción masiva, teniendo como eje central la relación costo-beneficio. Es el caldo de cultivo perfecto para que las empresas adquieran la idea de que a través de una producción con una calidad del producto media-baja y un volumen de exportación sin precedentes se consigue un margen de ganancias a considerar. De manera que el elemento sea alcanzable para la mayoría de la población, trasladándose a la configuración en las relaciones entre la humanidad y el medio donde se insertan. Ya no hace falta producir el alimento como se había hecho anteriormente, es menos costoso y más rentable importarlo a través de los grandes monopolios, no es necesario trabajar el campo y cuidar las fincas porque es imposible competir ante tales gigantes. Este factor fue clave en la consecución del éxodo rural y la devaluación del sector primario. El fenómeno de la globalización ha desvirtuado el tradicional modelo relacional ser humano - medio donde aquél dependía de las materias primas más próximas para su aprovechamiento.

Esta deslocalización generó una falta de motivación por el desarrollo socioeconómico a partir de los bienes potenciales y existentes, especialmente en las enmarcaciones rurales. Así como la propia búsqueda de aptitudes territoriales que promoviendo procesos innovadores puede favorecer una adecuación sostenible de las actividades y de los propios usos del suelo, donde a su vez se acaban generando nuevas perspectivas. Comenzaría entonces a llegar también esta concepción de desvinculación del espacio a Las Alpujarras, un siglo posterior al resto de España y dos después que en Europa, a mediados del siglo XX la decadencia de lo rural y lo autóctono era evidente. Sin embargo, esta verificación se reconoce como vital para conseguir mejorar la calidad de vida de la población y ante eso no hay discusión 
alguna. Pero siendo imprescindible preservar aquello que posibilita riqueza en este medio y que en un nuevo contexto puede servir como modelo de desarrollo rural y endógeno, sino actualmente por falta de las condiciones necesarias, en un futuro. La necesidad imperiosa de generar dinamismo a partir de los propios recursos territoriales es una cuestión primordial (Gore, 1984) para contrarrestar los efectos perniciosos del "capitalismo líquido". Es decir, la falta de un desarrollo local integrado, generado a partir de los recursos del entorno y respetando los ciclos naturales, lejos de la base existente del consumo excesivo y radicalmente global que menosprecia aquellas producciones que no se realizan en masa.

Cada municipio a pesar de pertenecer a una misma entidad superior (Alpujarra) posee una índole propia, una relación que viene determinada por múltiples factores que muestran sus diferentes realidades socioculturales, socioeconómicas y ambientales. Tales deslumbramientos traen consigo la esencia de una caracterización que puede integrarse (compartirse con otras comarcas) o no (endémico). En esta dicotomía el sentido de incorporación de bienes se amplía aún más, necesitando un trabajo de campo óptimo y un conocimiento profundo de los recursos potenciales. Por tanto, se específica la prospección de sólo un municipio alpujarreño (Ugíjar) como versión significativa de lo obtenido, citando nada más que aquellas cualidades en las que es posible discernir peculiaridades resaltables por su exclusividad territorial o particularidades destacadas comparativamente a nivel internacional, teniendo en cuenta también los reconocimientos de este tipo que pueden ir más allá de la zonificación en el ámbito (Tabla 4). Para ello serán prioritarias las conclusiones resultantes de un análisis integral de tal enclave a partir de la contextualización territorial e histórica, el medio biofísico, el medio socioeconómico, el sociocultural, junto a los usos del suelo y el paisaje, estos últimos resultantes de todos los factores anteriores. Teniendo en cuenta el poblamiento, su actuación sobre el espacio, la jerarquía y las relaciones. Después de verificar el proceso, se haría fehaciente la resolución propuesta para la delimitación de Ugíjar.

En la primera clasificación, obtenemos una serie de recursos que poseen algunas características diferidas a nivel internacional. No obstante, existen variedades categóricas dentro de este parámetro, de forma que en este caso sólo se señalan los de primer nivel y las que aportan una particularidad propia aplicable en tal contrastación. Estos se recogen en la Tabla 3.

Tabla 3

\section{PRINCIPALES RECURSOS QUE EL MUNICIPIO DE UGÍJAR COMPARTE CON OTROS TERRITORIOS BAJO EL CRITERIO DE SINGULARIDAD IDENTITARIA Y UNIVERSAL}

\begin{tabular}{|c|c|}
\hline RECURSOS & Rango geográfico donde se habitúa el recurso \\
\hline \multicolumn{2}{|c|}{ CONTEXTUALIZACIÓN TERRITORIAL E HISTÓRICA } \\
\hline \multicolumn{2}{|l|}{ Criterio: Repercusión territorial e histórica } \\
\hline $\begin{array}{l}\text { Remota posibilidad de la fundación de la } \\
\text { ciudad por el propio y popular Ulises con } \\
\text { el nombre de «Odysseia»vinculada a la } \\
\text { también transcendental obra «Odisea» }\end{array}$ & Sur de la Península Ibérica \\
\hline
\end{tabular}




\begin{tabular}{|c|c|}
\hline \multicolumn{2}{|c|}{ VEGETACIÓN NATURAL Y FAUNA } \\
\hline \multicolumn{2}{|l|}{ Criterio: Número de endemismos } \\
\hline $\begin{array}{l}\mathrm{N}^{\circ} \text { de endemismos no exclusivos. Una de las } \\
\text { comarcas con más biodiversidad de Europa. }\end{array}$ & Comarca Alpujarra granadina y almeriense \\
\hline \multicolumn{2}{|c|}{ Criterio: Grado de amenaza y excepcionalidad distributiva } \\
\hline $\begin{array}{l}\text { Malva de Las Alpujarras (Lavatera } \\
\text { oblongifolia Boiss). }\end{array}$ & $\begin{array}{l}\text { La Alpujarra, Sierra de Gádor, Sierra de La } \\
\text { Contraviesa y Sierra de Lújar }\end{array}$ \\
\hline Fartet (Aphaniusiberus) (Posible) & $\begin{array}{l}\text { Cuenca media-baja del Río Adra y río Villena } \\
\text { (Alicante) }\end{array}$ \\
\hline \multicolumn{2}{|c|}{ PRINCIPAL PATRIMONIO CULTURAL MATERIAL POTENCIAL } \\
\hline $\begin{array}{l}\text { Paisaje cultural: Comarca con más } \\
\text { tradición y exclusividad en el mundo } \\
\text { respecto a relaciones del carácter andalusí, } \\
\text { árabe y medieval. }\end{array}$ & \multirow[t]{6}{*}{ Comarca de La Alpujarra granadina y almeriense. } \\
\hline Rasgos generales destacados & \\
\hline $\begin{array}{l}\text { 1. Sistema de cultivo en paratas con muros } \\
\text { de piedra en balates, masas boscosas y } \\
\text { prados de alta montaña alternados. }\end{array}$ & \\
\hline $\begin{array}{l}\text { 2. Sistema de captación de agua en reservas } \\
\text { de nieve mediante la técnica del careo. }\end{array}$ & \\
\hline $\begin{array}{l}\text { 3. Asentamientos humanos escalonados } \\
\text { y adaptados al terreno, con presencia de } \\
\text { estructura y arquitectura urbana vernácula. }\end{array}$ & \\
\hline $\begin{array}{l}\text { 4. Masas de ribera asociadas a la red de } \\
\text { acequias y tradición agraria de la zona en } \\
\text { policultivos. }\end{array}$ & \\
\hline \multicolumn{2}{|c|}{ PRINCIPAL PATRIMONIO CULTURAL INMATERIAL POTENCIAL } \\
\hline \multicolumn{2}{|l|}{ Criterio: Modos de expresión } \\
\hline Léxico alpujarreño & Comarca Alpujarra granadina y almeriense \\
\hline \multicolumn{2}{|l|}{ Criterio: Alimentación/ Cocinas } \\
\hline D. O. P Miel de Granada & $\begin{array}{l}\text { En su máxima expresión aparece desde las cumbres } \\
\text { de Sierra Nevada a la costa en un recorrido vertical }\end{array}$ \\
\hline Plato alpujarreño & $\begin{array}{l}\text { Procedencia del Poqueira, embajador de la comarca } \\
\text { de Las Alpujarras }\end{array}$ \\
\hline
\end{tabular}

Elaboración propia.

En la contextualización territorial e histórica destaca el mito de la relación que posee con la transcendental figura de Ulises, quien más allá de visitar o transcurrir por el enclave según Estrabón fundaría la ciudad de "Odysseia". No existe una certeza de su localización actual (Vilariño Rodríguez, 2011) aunque algunos afamados historiadores como Fernández-Guerra la establecen en Ugíjar (Costa, 1895) vinculándola de este modo a la obra Odisea (Tabla 3). Una de las más conocidas y leídas junto a su personaje protagónico en la literatura occidental con una influencia apreciable en tal cultura, 
no en vano cuando se hace referencia al municipio suele aparecer este suceso ligado a su identificación. Por otra parte, en el caso de la biodiversidad, en lo que ocupa a tal circunscripción local su incorporación procede de las especies propias del sector alpujarreño gadorense. Aunque sus atribuciones más destacadas provienen de su localización en la cuenca media del río Adra. La culebra de collar (Natrix natrix), el zarcero pálido (Hippolais opaca) y otras como la posible presencia del fartet (Aphanius iberus) (Tabla 3) En Peligro a la extinción (EN) por la UICN en estado decreciente, son ejemplos de este enclave. Este último por la ubicación del ejemplar más cercano localizado y su probabilidad de dispersión, además de por su localización geográfica en tal cuenca (Oliva-Paterna, 2006; Citado por: Navarro y Oliva-Paterna, 2017), encontrándose diferenciaciones morfogenéticas respecto a la gran mayoría de poblaciones (Doadrio, Carmona, Fernández-Delgado, 2002; Citado por: Navarro, Oliva Paterna, 2017). En lo referido a la vegetación natural existe una planta muy representativa y que se encuentra En Peligro a la extinción (EN) por la UICN en estado decreciente, la denominada malva de Las Alpujarras (Lavatera oblongifolia Boiss) (Tabla 3).

El patrimonio cultural material a resaltar es sin duda el catalogado como paisaje cultural (Tabla 3). Resultado de una serie de influencias culturales permanentes, de más de diez siglos, con una continua adaptación del ser humano a las exigencias del medio donde se enmarcan bienes y valores que representan sus diferentes fases de evolución. La técnica del careo por su parte se visualiza en la circunscripción local en su última fase funcional. El emplazamiento no posee ninguna acequia de careo porque se sitúa en el piedemonte de Sierra Nevada, tal y como afirma la comunidad de regantes, pero sí forma parte de la función de estas indirectamente por la integración de los aportes que finalmente acaban aguas abajo pudiendo contribuir al ciclo hidrogeológico. La composición y caracteres de los núcleos urbanos vernáculos se dan principalmente en Jorairátar que necesita una planificación urbana más conservacionista. Los bosquetes de ribera y el policultivo por su parte se dañan con la cementación de acequias y principalmente por el entubado de estas.

Tabla 4

\section{RECONOCIMIENTOS INTERNACIONALES COMPARTIDOS Y PROPIOS DEL MUNICIPIO DE UGÍJAR}

\begin{tabular}{|l|c|c|l|}
\hline \multicolumn{1}{|c|}{ RECURSOS } & Reconocimiento & Propio o compartido & \multicolumn{1}{c|}{ Territorio } \\
\hline Criterio: Oficios y saberes & Compartido & $\begin{array}{l}\text { Croacia, Chipre, } \\
\text { Francia, Grecia, Italia, } \\
\text { Eslovenia, España y } \\
\text { Suiza }\end{array}$ \\
\hline $\begin{array}{l}\text { Conocimientos y } \\
\text { técnicas del arte de } \\
\text { construir muros de } \\
\text { piedra seca }\end{array}$ & UNESCO & Compartido & $\begin{array}{l}\text { Andalucía cuna del } \\
\text { flamenco. Raíces } \\
\text { también en otras } \\
\text { comunidades como } \\
\text { Murcia y Extremadura. }\end{array}$ \\
\hline Criterio: Modos de expresión
\end{tabular}




\begin{tabular}{|l|c|c|l|}
\hline \multicolumn{4}{|l|}{ Criterio: Alimentación y cocinas } \\
\hline La dieta mediterránea & UNESCO & Compartido & Países mediterráneos \\
\hline $\begin{array}{l}\text { Vinos Bodega } \\
\text { "Dominio } \\
\text { Buenavista" }\end{array}$ & $\begin{array}{c}\text { Premios internacionales } \\
\text { a mejores vinos }\end{array}$ & Propio & Municipio de Ugíjar \\
\hline
\end{tabular}

Elaboración propia.

En relación a los que dentro de su género no se repiten y son capaces de crear una identidad territorial diferenciada al más alto nivel se dan los que se muestran en la tabla 5:

\section{Tabla 5}

PRINCIPALES RECURSOS ENDÉMICOS DEL MUNICIPIO DE UGÍJAR

\begin{tabular}{|l|}
\hline \multicolumn{1}{|c|}{ BIOCLIMA Y VEGETACIÓN NATURAL } \\
\hline Criterio: Grado de amenaza y excepcionalidad distributiva. Originalidad del bioclima \\
\hline $\begin{array}{l}\text { Bioclima xérico oceánico de termotipo mesomediterráneo con ombrotipo semiárido y vegetación } \\
\text { potencial de lentiscares con serie BgPl }\end{array}$ \\
\hline Siempreviva de Ugíjar (Limonium ugijarense Erben) \\
\hline \multicolumn{1}{|c|}{ PATRIMONIO CULTURAL INMATERIAL DE INTERÉS POTENCIAL } \\
\hline Criterio: Rituales Festivos \\
\hline Nacimiento de la Advocación a la Virgen del Martirio \\
\hline Criterio: Alimentación/ Cocinas con una exclusividad identitaria singular \\
\hline Molío \\
\hline Arroz Liberal \\
\hline
\end{tabular}

Elaboración propia.

El bioclima que presenta la delimitación posee una enorme excepcionalidad e identidad municipal no existiendo como mínimo en ningún municipio andaluz que lo adhiera de manera específica como propio en su asociación a la vegetación potencial correspondiente, siendo este un descubrimiento que aparece por primera vez en una revista científica. Tal bioclima es el xérico oceánico de termotipo mesomediterráneo con ombrotipo semiárido y serie Termo-mesomediterránea alpujarreño-gadorense, filábrico-nevadense y almeriense, semiárido-seca del lentisco (Pistacialentiscus: Bupleurogibraltarici-Pistacietolentisci S.). (Junta de Andalucía, 2003a) (Tabla 5). La vegetación natural de Ugíjar alberga al único endemismo vegetal exclusivo de La Alpujarra, con área de distribución restringida a tal entidad local, sus poblaciones pueden verse amenazadas por actividades como los invernaderos. Se trata de la denominada siempreviva de Ugíjar (Limounium ugijarense Erben) (Tabla 5).

En los rituales festivos aparece el surgimiento de la Advocación de la Virgen del Martirio (Tabla 5) como una novedad que alcanza una tradición ya de más de cuatro siglos, lo que supone un hito histórico que se suma al elenco de las revelaciones oficiales de la 
iglesia católica (Hitos, 1999; Vizuete Mendoza, 2012). A lo que hay que añadir el alcance de una identidad de origen propio vinculada a este municipio. Posee también rasgos que le otorgan una gran autenticidad como el autonombramiento que según la tradición la Santísima Virgen efectúa al ser encontrada en el pozo, las marcas visibles que presenta y el color de la tez provenientes de los desagravios y su martirio. Por lo demás, el contexto es similar a la Virgen de Los Mártires. El Papa Benedicto XVI adjudicó en 2006 al Santuario un año jubilar y en 2007 se realizó la conmemoración canónica.

En la parte gastronómica, referirse al molío (Tabla 5) y sobre todo al arroz liberal (Tabla 5) es sinónimo de relación e identificación con este territorio (Espinosa Carmona, 2012; Gázquez Expósito, 2008). En el primero existen algunas semejanzas en otras partes de España, pero con particularidades en cuanto a los ingredientes y a ese toque típico de condimentación. El segundo a pesar de haberse extendido por otras partes de Andalucía parece resguardarse de la extinción aquí. Para hacerlo de manera acorde hay que seguir los cánones de los expertos en la materia, ya que a pesar de usar los ingredientes adecuados hay que saber utilizarlos en el instante y con la proporción justa. Aspecto que distancia un plato que refleja la esencia tradicional de uno mediocre, con sabores y texturas poco intrínsecas del original, estos se han transmitido de generación en generación, realizándose aún hoy día. Este último corre cierto riesgo de desaparecer en su elaboración tal y como mandan los cánones, ya que cada vez son menos los jóvenes que se aventuran a llevarlo a cabo.

Para finalizar es necesario exponer que hasta el momento y según la información que maneja la corporación municipal, los principales atrayentes turísticos para la delimitación son estacionales, enmarcándose dentro de la tipología de eventos y espectáculos. Una con la categoría de feria de muestras denominada ExpoAlpujarra, y otra de carácter religioso, con motivo de la celebración de las fiestas en Honor a la Santísima Virgen del Martirio patrona de Las Alpujarras, destacándose dentro de la primera la mayor tendencia por el consumo de comestibles artesanales. Entre los recursos turísticos más conocidos hasta el momento se dan el Centro de Interpretación del Patrimonio Cultural de La Alpujarra, el Registro de Archivos Históricos de La Alpujarra, la iglesia de la Virgen del Martirio, la ermita de San Antón y el acueducto de los Arcos. De manera esporádica se utiliza la casa de Doña Loreto con la exposición etnográfica más importante de La Alpujarra.

\section{CONCLUSIONES}

El documento cumple con la intención con la que se elaboró, ya que se ha conseguido aplicar con éxito el criterio de singularidad identitaria y universal sobre los recursos, reflejando a la población la importancia de las manifiestas y llamativas cualidades que se presentan en el territorio donde viven. Aspectos que pasan desapercibidos en muchos casos por el desconocimiento y la falta de cultura territorial, estos rasgos pueden y deben formar parte de una estrategia de desarrollo rural turística. El enfoque de la investigación permite buscar diferenciaciones territoriales a diversas escalas, siendo útil para crear una imagen de presentación y de distinción comarcal o municipal. Además deja entrever la capacidad de las empresas rurales para competir con otras de mayor entidad mediante la idea de calidad con productos arraigados en la zona. Se trata esta de una forma especial 
de discriminar, clasificar y valorar los bienes, ya que sólo utiliza un criterio y lo escenifica en su máxima expresión, lo que nos ayuda a entender que elementos son verdaderamente propios, cuáles poseen unas peculiaridades llamativas excepcionales y los que están reconocidos por instituciones y organismos internacionales como la UNESCO. Cuestiones que vienen a colación y que son aplicables al tema de la banalización y pérdida de identidad en los territorios, exhibiendo en que elementos aplicar los máximos esfuerzos de conservación y/o protección ante una posible pérdida definitiva.

La importancia de lo local se hace evidente en tal artículo y es que es necesario diferenciar lo comarcal de lo municipal, ya que este último puede poseer recursos que no comparte con la primera y que le otorgan una entidad propia, circunstancias que en ocasiones pasan desapercibidas por la planificación local. Estas investigaciones pueden fomentar la diversidad patrimonial de la comarca por medio de una mayor profundización de tal escala geográfica como se ha demostrado con la circunscripción de Ugíjar. A destacar descubrimientos como la excepcionalidad de su bioclima y aportaciones respecto a La Alpujarra en relación a la peculiaridad de la relación de los pisos bioclimáticos con la miel, entre otros. Es momento de exponer ciertas adversidades que se han ido solucionando, en lo que se refiere a las excepcionalidades por medio del análisis de algunas de las diferentes configuraciones territoriales. En el caso socioeconómico se descartan las exportaciones supranacionales de productos, incluso también los artesanales con gran tradición, como un rasgo distintivo internacional. Y es que desde ese punto de vista se han considerado los premios de esta índole, entendemos que la importación de productos al extranjero es una normalización en nuestro sistema económico actual y no una excepción. Es algo habitual que las empresas del siglo XXI necesitan para superar recesiones económicas y expandir sus productos. Se pueden rescatar en este aspecto algunas iniciativas que se están haciendo con productos con arraigo como los dulces alpujarreños directamente con otros comerciales alemanes o la venta de los llamados tejidos alpujarreños por internet. En los premios internacionales se ha intentado distinguir aquellos más relevantes, priorizando además la existencia de una verdadera competición entre diferentes países y no por círculos seccionados por cada país (competición nacional fuera de España).

En cuanto a la parte sociocultural, concretamente en el patrimonio inmaterial es necesario explicar porque no se presentan recursos que popularmente parecieran que podrían estar bajo el criterio aplicado, nos referimos a los dulces alpujarreños, el trovo y los tejidos textiles de esta misma comarca, entre otros, que sin duda forman parte y de manera importante del extenso folclore de este ámbito subregional. La respuesta desde un punto de vista general después de un gran esfuerzo de reflexión y clarificación de ideas se puede visualizar desde varios puntos clave. A ninguna de las manifestaciones se les puede atribuir con certeza un origen respecto a La Alpujarra, además de no mostrar diferenciaciones lo suficientemente marcadas, documentadas y contrastadas como propias de la zona para otorgarles una identidad singular o exclusiva. A lo que se añade la carencia de unos oficios, saberes o técnicas que los hayan diferenciado de otras zonas fuera de la comarca acordes con la tradición de la que proceden y no son a día de hoy el único enclave conocido o el último reducto que los alberga respecto a su tradición.

El municipio de Ugíjar elogia un campo de acción factible en muchos de los aspectos más demandados por los visitantes teniendo en cuenta que los recursos con dotes más 
originales y particulares pueden motivar el advenimiento de viajeros, sobre todo si hay una buena estrategia o producto turístico aparejado. Sin embargo, en este aspecto queda mucho por hacer aún en el enclave, este posee una marcada estacionalidad unida principalmente a los eventos (Feria de muestras ExpoAlpujarra y celebración de las fiestas en Honor a la Santísima Virgen del Martirio). Por tanto es necesario elaborar medidas que sigan fomentando la llegada de estos, diversificando y mejorando la oferta y aprovechando los recursos. Existe en numerosas ocasiones una falta de convencimiento sobre la capacidad de desarrollo que posibilitan estas manifestaciones ante un cada vez turista más exigente. Prueba de ello es la pérdida patrimonial irreversible que se produce paulatinamente por la falta de comprensión de estos aspectos en los Planes Generales de Ordenación Urbana. Es de apreciar una externalidad crucial que afecta directamente al ámbito, como es el incremento de las líneas internacionales aéreas en la capital siendo un hecho esperanzador para la entrada de más viajeros. A pesar de ello, hay que seguir mejorando las conexiones por carretera entre el tridente (Alpujarras - Granada capital - Costa Tropical), pudiendo provocar un potencial beneficioso para el enclave. Por último, subrayar que la práctica innovadora de esta metodología propia, en la persistencia de los valores universales y de gran valor identitario justificada bajo un análisis integral, no pretende menospreciar otros bienes que no posean tales determinaciones. Ya que una base irrefutable dentro de la ordenación del territorio y específicamente en el desarrollo local endógeno se sostiene en el intento de la creación de riqueza aprovechando todo el potencial posible que este ofrece. Manteniendo la interpretación de que todos complementan y contribuyen a la consecución de una meta final. En este caso, un desarrollo turístico sostenible.

\section{BIBLIOGRAFÍA}

ADR ALPUJARRA ALMERIENSE: Alpuguia. Consultada el 15 de Enero, 2019. Disponible en http://www.alpuguia.com

ALBURQUEQUE, F. (1999): Identidad y Territorio. Madrid, Instituto de Economía y Geografía, Consejo Superior de Investigaciones Científicas.

AYUNTAMIENTO DE GRANADA (2018): «Datos turísticos Granada INE». Encuesta de Ocupación Hotelera. Consultado el 15 de noviembre, 2018. Disponible en http:// www.Granadatur.com/page/313-datos-turisticos-granada-ine/

CABELLO, J., GIMÉNEZ, E. y ALCARAZ, D. (2010). «Limonium ugijarense Erben», en Atlas y Libro Rojo de Flora Vascular Amenazada de España, Tomo I. Inventario Español de Especies Terrestres, pp. 766-767.

CARRERA, G (2009a): «Atlas del Patrimonio Inmaterial de Andalucía: puntos de partida, objetivos y criterios técnicos y metodológicos», PH: Boletín del Instituto Andaluz de Patrimonio Histórico, vol. 17, pp. 19-41.

CARRERA, G. (2009b): «Iniciativas para la salvaguardia del Patrimonio Inmaterial en el contexto de la Convención UNESCO, 2003: una propuesta desde Andalucía». Instituto Andaluz del Patrimonio Histórico, pp. 179-195.

CASTILLO MARTÍN, A. (2004): «Itinerario hidrogeológico a través de la carretera más alta de Europa: Granada-Sierra Nevada (Veleta)». Hidrogeología y Recursos Hidráulicos, XXVII, p. 301. 
CEBRIÁN ABELLÁN, F. y GARCÍA GONZÁLEZ, J. A (2010): «Propuesta metodológica para la identificación, clasificación, y puesta en valor de los recursos territoriales del turismo interior. La provincia de Albacete», Boletín de la Asociación de Geógrafos Españoles, $\mathrm{n}^{\circ}$ 54, pp. 361-383.

COSTA, J. (1895): Estudios Ibéricos (La servidumbre entre los Iberos. Litoral ibérico del Mediterráneo en el siglo VI-V antes de Jesucristo). Madrid, Tipografía de San Francisco de Sales, pp. 55, 67, 68, 69.p. 162

CROSBY, A. (1993): El desarrollo turístico sostenible en el medio rural. Madrid, Centro Europeo de Formación Ambiental y Turística.

DOADRIO, I., CARMONA, J. A. y FERNÁNDEZ-DELGADO, C. (2002): «Morphometric study of the Iberian Aphanius (Actinopterygii, Cyprinodontiformes), with description of a new species». Folia Zoologica, vol. 51 (1), pp. 67-79.

DURÁN, E. (2010): Plan de Desarrollo y Consolidación de la Producción Ecológica en La Alpujarra-Sierra Nevada, (Granada). Grupo de Desarrollo Rural de la AlpujarraSierra Nevada, (Granada), pp. 1-15.

ESPINOSA CARMONA, C. (2012): Breve guía de fiestas y gastronomía de La Alpujarra Granadina. ADR Alpujarra-Sierra Nevada de Granada.

ESTRABÓN (29 - 7 A. C): Geographika. Libro III, capítulos 2, 3, 4 y 13. p. 162

FERIA TORIBIO, J. M. (2010): «Patrimonio territorial y desarrollo sostenible: un estudio comparativo en Iberoamérica y España». Estudios Geográficos, n 268, p. 129-159.

FERNÁNDEZ DE CORDOBA, M. B., CLUSA Y ORIACH, J., FERIA TORIBIO, J. M. y VEGA GONZÁLEZ, G. (1986): Sistema de ciudades. Sevilla, Dirección General de Ordenación del Territorio y Consejería de Política Territorial.

FERNÁNDEZ ONDOÑO, E., MARTÍN PEINADO, F., SIERRA ARAGON, M., MARTINEZ GARZÓN, F. J., ORTEGA BERNALDO DE QUIRÓS, E., ORTIZ BERNAD, I., SEVILlA PEREA, A. y LORITE MORENO, J. (2015): «XXX Reunión de la Sociedad Española de la Ciencia del Suelo. Cuaderno de Campo». Departamento de Edafología y Química Agrícola de la Universidad de Granada, p. 23. Consultado el 8 de abril, 2019. Disponible en http://www.secs.com.es/wp-content/uploads/2016/02/30Reuni\%C3\%B3n-Granada-2015. pdf

FLORA IBÉRICA, FUNDACIÓN BIODIVERISIDAD, REAL JARDÍN BOTÁNICO (AGENCIA ESTATAL CONSEJO SUPERIOR DE INVESTIGACIONES CIENTÍFICAS). Sistema de Información sobre Plantas de España (Anthos). Consultado el 3 de noviembre, 2018. Disponible en http://www.anthos.es/

FRANÇOIS, H. (2004): «Le tourisme durable une organisation du tourisme en milieu rural», Revue d'Économie Régionale \& Urbaine, $\mathrm{n}^{\circ}$ 1, pp. 57-80.

GARCÍA CUESTA, J. L. (2003): «El vino como recurso endógeno en el desarrollo turístico comarcal», en El enoturismo ¿Una moda pasajera?. Seminario II Semana Internacional del vino y la viña. Aranda, p. 62.

GARCÍA HENCHE, B. (2005): «Características diferenciales del producto turismo rural», Cuadernos de Turismo, $\mathrm{n}^{\circ} 15$, pp. 113-133.

GÁZQUEZ EXPÓSITO (2008): «Patrimonio gastronómico de La Alpujarra», en García Lorca, A. y Matarín Guil, A. S. (eds.), La Alpujarra Oriental: La gran desconocida. Universidad de Almería y Ayuntamiento de Alboloduy, pp. 85-88. 
GORE, C. (1984): Regions in Question. Space, Development Theory and Regional Policy. Londres y Nueva York, Methuen, pp. 422-427.

HAYA, E., BUIRA, A., FRAGA i ARQUIMBAU, P., GARCÍA MURILLO, P. G. y RIVERS, M. C. (2017): Lavatera oblongifolia. La Lista Roja de Especies Amenazadas 2017 de la UICN: e. T96437005A96437552. Consultado el 15 de Marzo, 2019. Disponible en http://dx. doi. org/10. 2305/IUCN. UK. 2017-3. RLTS. T96437005A96437552. en. HERITAGE (2014): La Alpujarra paisaje cultural. Proyecto Culturmed. Anexo 1 y 2. Programa de Cooperación Transfonteriza.

HERITAGE (2015): Alpujarra Paisaje Cultural, Descripción y justificación de los elementos que conforman el valor universal excepcional del paisaje cultural de La Alpujarra. POCTEFEX. Proyecto cofinanciado por el Fondo Europeo de Desarrollo Regional (FEDER) en el marco del Programa Operativo de Cooperación Transfronteriza. España. Fronteras Exteriores, pp. 99, 100, 147-203. Consultado el 10 de octubre, 2018. Disponible a través de documento web: https://issuu. com/poctefex/docs/ alpujarrapaisajecultural

HITOS, F. (1999): « Capítulo IX. Virgen del Martirio», en Mártires de la Alpujarra en la Rebelión de los moriscos: (1568) ensayo introductorio, Manuel Barrios Aguilera. Alicante. Biblioteca Virtual Miguel de Cervantes. Consultado el 13 de noviembre, 2018. Disponible en http://www.cervantesvirtual.com/nd/ark:/59851/bmc5m639

INSTITUTO ANDALUZ DE PATRIMONIO HISTÓRICO (2009): «Oficios y saberes de La Alpujarra» Información documental de: García Muñoz, A. B. Atlas del Patrimonio Inmaterial de Andalucía. Consultado el 20 de octubre, 2018. Disponible en http://www. iaph.es/patrimonio-inmaterial-andalucia/frmSimple.do

INSTITUTO ANDALUZ DE PATRIMONIO HISTÓRICO (2012): Atlas de Patrimonio Inmaterial de Andalucía. Sevilla, Junta de Andalucía. Consejería de Cultura.

INSTITUTO ANDALUZ DE PATRIMONIO HISTÓRICO (2012): Atlas de Patrimonio Inmaterial de Granada. Consejería de Cultura, Junta de Andalucía, Gr, pp. 38, 39.

INSTITUTO DE ESTADÍSTICA Y CARTOGRAFÍA DE ANDALUCÍA (IECA). Datos Espaciales de Referencia en Andalucía (DERA). Junta de Andalucía. Consultado el 31 de septiembre, 2018. Disponible en https://www.juntadeandalucia.es/institutodeestadisticaycar tografia/DERA/

INSTITUTO GEOGRÁFICO NACIONAL, ASOCIACIÓN DE GEÓGRAFOS ESPAÑLES (1990): «Endemismos Generales» Mapa incluido. Asociación de Geógrafos Españoles y Gobierno de España.

JUNTA DE ANDALUCÍA (2003a): Datos climáticos aplicados a la Gestión del Medio Natural Andaluz I: Bioclimatología y biogeografía. Sevilla, Consejería de Medio Ambiente.

JUNTA DE ANDALUCÍA (2003b): La demanda del turismo rural en Andalucía. Sevilla, Consejería de Turismo, Comercio y Deporte. Sistema de Análisis y Estadística del Turismo de Andalucía (SAETA), pp. 60-82.

JUNTA DE ANDALUCÍA (2010): Plan de Zona Rural a Revitalizar de la Comunidad Autónoma de Andalucía. Programa de Desarrollo Rural Sostenible 2010-2014, pp. 101-118. 
LENO CERRO, F. (1993): Técnicas de evaluación del potencial turístico. Madrid, Ministerio de Industria, Comercio y Turismo.

LUQUE GIL, A. y NAVARRO JURADO, E. (2011): Guía para el análisis de los recursos territoriales turísticos. Málaga, Universidad de Málaga.

MARTÍNEZ ARNÁIZ, M., BARAJA RODRÍGUEZ, E. y MOLINERO HERNANDO, F. (2019): «Criterios de la UNESCO para la declaración de regiones vitícolas como paisaje cultural: su aplicación al caso español», Boletín de la Asociación de Geógrafos Españoles, n 80, pp. https://bage. age-geografia. es/ojs/index. php/bage/article/ view/2614/2527

MINISTERIO DE AGRICULTURA, PESCA Y ALIMENTACIÓN (2016): Pliego de condiciones de la Denominación Protegida Miel de Granada. Madrid, Dirección General de Alimentación, pp. 1-14.

MINISTERIO DE AGRICULTURA, PESCA, ALIMENTACIÓN Y MEDIO AMBIENTE. «Parque Nacional de Sierra Nevada». Consultado el 5 de noviembre, 2018. Disponible enhttp://www.mapama.gob.es/es/red-parques-nacionales/nuestros-parques/ sierra-nevada/

MOTA, J. F., CABELlO, J., DYONANTE, C. y CUETO, M. (1999): «Criterios técnicos para la ordenación de los recursos naturales, uso y gestión de los subdesiertos de Almería», en Investigación y desarrollo medioambiental en Andalucía. Almería, Universidad de Almería, 55-92.

NAVARRO JURADO, E. (2016): «Técnicas e instrumentos de planificación territorial de áreas turísticas», en M. Simancas (Coord.), La planificación y gestión territorial del turismo. Madrid, Síntesis, pp. 133-174.

NAVARRO VALVERDE, F. A. (2015): Recursos Territoriales Turísticos del Mundo. Granada, Avicam.

NAVARRO, A. R. y OLIVA PATERNA, F. J. (2017): «Fartet - Aphanius Iberus», en Enciclopedia Virtual de los Vertebrados Españoles. Sanz, J. J., Oliva Paterna, F. J. (Eds.). Museo Nacional de Ciencias Naturales, Madrid. Consultado el 15 de Marzo, 2019. Disponible en: http://www.vertebradosibericos.org/

OBSERVATORIO DE TURISMO RURAL (2017): El turismo rural en Andalucía. Escapada rural. com, EUHT CETT-UB y Netquest, Informe, pp. 1-22.

OBSERVATORIO TURÍSTICO DE LA PROVINCIA DE GRANADA (2016):Memoria anual del observatorio turístico. Patronato Provincial de Turismo de Granada, pp. 108-151.

OLIVA-PATERNA, F. J. (2006): Biología y Conservación de Aphaniusiberus (Valenciennes, 1846) en la Región de Murcia. Tesis Doctoral, Universidad de Murcia.

ORGANIZACIÓN MUNDIAL DEL TURISMO (2004): Rural Tourism in Europe: Experiences, Development and Pespectives. AbstractMonograph WTO. Consultado el 20 de Diciembre, 2018. Disponible en https://www.e-unwto.org/doi/book/10. $18111 / 9789284407163$

ORTEGA VALCÁRCEL, J. (1999): «El patrimonio territorial: El territorio como recurso cultural y económico». Ciudades. Revista del Instituto de Urbanística de la Universidad de Valladolid, $\mathrm{n}^{\circ}$ 4, pp. 31-48. 
PATRONATO PROVINCIAL DE TURISMO DE GRANADA (2016): Memoria de actividades anuales. Diputación de Granada, pp. 1-69.

PATRONATO PROVINCIAL DE TURISMO DE GRANADA: «Romería de la Virgen de las Nieves». Consultado el 31 de noviembre, 2018. Disponible en http://www. turgranada.es/fichas/romeria-de-la-virgen-de-las-nieves/

RODRÍGUEZ, F. (2008): «Ámbito territorial de La Alpujarra Granadina Oriental. Almería», en García Lorca, A. y Matarín Guil, A. (Eds.), La Alpujarra Oriental: La gran desconocida. Almería, Universidad de Almería y Ayuntamiento de Alboloduy, pp. $12-24$.

SECRETARÍA GENERAL DE ORDENACIÓN DEL TERRITORIO Y CENTRO DE ESTUDIOS DE PAISAJE Y TERRITORIO (2014): «Alpujarra Granadina», en Catálogo de paisajes de la provincia de Granada. Junta de Andalucía, Consejería de Medio Ambiente y Ordenación del Territorio, Universidad de Sevilla, pp. 219-230.

SHARPLEY, R. y SHARPLEY, J. (1997): Rural tourism. An introduction. Bedfordshire, International Thomson Business Press.

SILVA, R., FERNÁNDEZ, V. y MATA, R. (2018): «Concepto, ámbito y significado de los paisajes patrimoniales», en Molinero, F. y Tort J. (Coords.) Paisajes patrimoniales de España. Madrid, Ministerio de Agricultura, Pesca y Alimentación, Ministerio para la Transición Ecológica y UAM Ediciones, pp. 17-40.

SPANHI, J. C. (1959): L'Alpujarra - sécrèteAndalousie. Neuchatel, Ed. de la Banconnière. TITOS MARTÍNEZ, M. y MARTÍN VIDA, M. A. (2007): « Un viajero alemán en la alpujarra en 1765», Revista del Centro de Estudios Históricos de Granada y su Reino, $\mathrm{n}^{\mathrm{o}} 19$, pp. 283-297.

TRILLO SAN JOSÉ, C. (1999): « El paisaje vegetal en la Granada Islámica y sus transformaciones tras la conquista castellana», Historia Agraria, n $^{\circ}$ 17, pp. 131-152.

UIOOT (1970): Estudio sobre la Oferta Potencial Internacional de los Recursos de los Recursos Turísticos. Ginebra, Unión Internacional de Organismos Oficiales de Turismo.

UNESCO (2003a): Convención para la Salvaguardia del Patrimonio Cultural Inmaterial. París.

UNESCO (2018b): Elementos en las listas de patrimonio cultural inmaterial. Consultado el 15 de marzo, 2019. En https://ich. unesco. org/es/estado/espana-ES?info=elementosen-las-listas

VALLE, F., MADRONA, M. T. y SALAZAR, C. (1993): «Algunas formaciones boscosas del sudeste de la Península Ibérica: Los alcornocales del Haza del Lino (La Contraviesa) y de la Sierra del Jaral (Lújar)». Congreso Forestal Español. Tomo 1, p. 454

VERA, J., LÓPEZ, F., MARCHENA, M. y ANTÓN, S. (2011): Análisis territorial del turismo y planificación de destinos turísticos. Valencia, Tirant lo Blanch.

VILARIÑO RODRÍGUEZ, J. J. (2011): «La Península Ibérica y los héroes griegos en la obra estraboniana». Universidad de Salamanca. Estudios de Historia Antigua, 29, pp. 188, 194. Página 165. VIZUETE MENDOZA, J. C. (2012): «Nuestra Señora del Martirio de Ugíjar (Granada): Origen, voto y fiesta», en Advocaciones Marianas de Gloria. SIMPOSIUM (XX ${ }^{\mathrm{a}}$ Edición), San Lorenzo del Escorial. Toledo, Universidad de Castilla-La Mancha, pp. 121-138. 
